Article

\title{
Dual-Band Plasmonic Perfect Absorber Based on Graphene Metamaterials for Refractive Index Sensing Application
}

\author{
Zao Yi ${ }^{1,2, \dagger}$, Cuiping Liang ${ }^{1,2,+}$, Xifang Chen ${ }^{1,2}$, Zigang Zhou ${ }^{1,2}$, Yongjian Tang ${ }^{1,2}$, Xin Ye ${ }^{3}$, \\ Yougen $\mathrm{Yi}^{4}{ }^{4}$, Junqiao Wang ${ }^{5}$ and Pinghui $\mathrm{Wu}^{6, *}$ \\ 1 Joint Laboratory for Extreme Conditions Matter Properties, Southwest University of Science and Technology, \\ Mianyang 621010, China \\ 2 Sichuan Civil-Military Integration Institute, Mianyang 621010, China \\ 3 Research Center of Laser Fusion, China Academy of Engineering Physics, Mianyang 621010, China \\ 4 College of Physics and Electronics, Central South University, Changsha 410083, China \\ 5 School of Physics and Engineering and Key Laboratory of Materials Physics of Ministry of Education of \\ China, Zhengzhou University, Zhengzhou 450001, China \\ 6 Photonic Technology Research \& Development Center, Key Laboratory of Information Functional Material \\ for Fujian Higher Education, Quanzhou Normal University, Quanzhou 362000, China \\ * Correspondence: phwu@zju.edu.cn; Tel./Fax: +86-0595-22003815 \\ + These authors contribute equally to this article.
}

Received: 15 May 2019; Accepted: 25 June 2019; Published: 2 July 2019

check for updates

\begin{abstract}
We demonstrate a dual-band plasmonic perfect absorber (PA) based on graphene metamaterials. Two absorption peaks $(22.5 \mu \mathrm{m}$ and $74.5 \mu \mathrm{m})$ with the maximal absorption of $99.4 \%$ and $99.9 \%$ have been achieved, respectively. We utilize this perfect absorber as a plasmonic sensor for refractive index (RI) sensing. It has the figure of merit (FOM) of 10.8 and 3.2, and sensitivities of about 5.6 and $17.2 \mu \mathrm{m} / \mathrm{RIU}$, respectively. Hence, the designed dual-band PA-based RI sensor exhibits good sensing performance in the infrared regime, which offers great potential applications in various biomedical, tunable spectral detecting, environmental monitoring and medical diagnostics.
\end{abstract}

Keywords: surface plasmon resonance; graphene; refractive index sensor; metamaterials

\section{Introduction}

Surface plasmon resonance (SPR) is the interaction between electromagnetic fields and free electrons in metals [1]. With the development in nano-fabrication technology, SPR has been widely used in the field of optical applications, biological analysis, photocatalysis, and chemical detection [2-8]. Due to SPR being extremely sensitive to a small change in the refractive index of surrounding medium, many works concentrate on the application of sensing technology [9,10]. As a two-dimensional material with only one atom thickness packed in a honeycomb lattice, graphene has multitude of exceptional electronic and optical properties because of its unique electronic band structures [11-15]. Graphene can excite surface plasmons like metals, but unlike metals the surface plasmons of graphene are tunable. Therefore, graphene can replace metal as a plasmonic sensor. It is common to use the perfect absorption structure of plasmon for sensing. The perfect absorber is a subject worth researching. Perfect absorption can be realized by optimizing the shape, size, and optical properties of the metamaterials of the perfect absorber (PA) [16-19]. So far, there are many studies on perfect absorbers, including simulations and experiments. For example, in 2011, Zhang et al. designed and manufactured a near-infrared dual-band plasma absorber [20]. In addition, in 2019, Xu et al. proposed and fabricated a metamaterial nearly perfect absorber in the visible and near-infrared region [21]. These reported experimental 
measurements match well with the simulations. Once the metal structure is fabricated, the resonant wavelength and operating range will be unchangeable. Since graphene has many advantages over metals, we chose it as the research material. At the same time, the perfect absorber with graphene metamaterial can have good refractive index sensing performance. When the refractive index of the environment changes, the perfect absorption is destroyed, thus realizing sensing.

However, at present, many works only operate an a single wavelength, which greatly hinders their application in practice. In many applications, when multiple absorption bands can be monitored, it is convenient to correlate and study structural changes between different molecular regions and is critical to the accurate identification of molecular species [22-25]. Therefore, from the viewpoint of application, a PA structure with dual or multiple bands is highly advantageous for many occasions.

To this end, we theoretically design a dual-band plasmonic perfect absorber (PA) based on graphene metamaterials in the infrared regime. We obtain two absorption peaks located at $\lambda_{1}=22.5 \mu \mathrm{m}$ and $\lambda_{2}=74.5 \mu \mathrm{m}$ with high absorption coefficients of $99.9 \%$ and $99.4 \%$ respectively. The spectral location of the absorption values can be adjusted actively by tuning the graphene's Fermi level without changing the geometric parameters of the structure. Besides, the resonant wavelengths of two modes are very sensitive to changes of environmental refractive index. It has the figure of merit (FOM) of 10.8 and 3.2, and sensitivities of about 5.6 and $17.2 \mu \mathrm{m} / \mathrm{RIU}$ (refractive index unit) respectively. The PA-based RI sensor has narrower FWHM (FWHM is the full width of half maximum) than an ordinary absorption sensor, which means the RI sensor has better sensing performance. Hence, the proposed PA-based RI sensor can offer great potential applications in biomedicine, environmental monitoring and medical diagnostics.

\section{Structure Design and Numerical Model}

The finite-difference time-domain (FDTD) method is employed to analyze the optical response in the graphene structures. TM-polarization indicates that the direction of the incident electric field is along the $x$ axis. In the FDTD simulation calculations, the accuracy of mesh in the graphene layer along the $x(y)$ and $z$ axes are set to 25 and $0.2 \mathrm{~nm}$. The anti-symmetric and symmetric boundary conditions were respectively adopted in the $x$ and $y$ directions. The boundary conditions of the perfectly matched layer are used in the $z$ direction along the propagation of the incident plane wave.

The geometry of the PA-based RI sensor is depicted in Figure 1. From bottom to top, there is a Si $\left(n_{1}=3.4\right)$ layer, a gold mirror, a $\mathrm{SiO}_{2}\left(n_{2}=1.97\right)$ layer and a periodical graphene pattern tightly stacked to form this structure. Since this structure excites the local surface plasmons, the graphene surface plasmon is confined to the graphene surface-that is to say it does not pass through the $\mathrm{SiO}_{2}$ or even reach the gold surface. What really reaches the gold surface should be part of the incident light. One part of the light in the incident light interacts with the graphene. The other part passes through the graphene to reach the gold surface, which is reflected back by the gold and then lost in the $\mathrm{SiO}_{2}$. We chose the lowermost layer as the most common material, Si [26]. Its function can be understood as a substrate or a buffer layer to protect the whole device against accidental mechanical damage.

The geometric structure we designed is simple and easy to manufacture. At the same time, considering manufacturing tolerances, we should allow the gap between unit cells to be greater than $100 \mathrm{~nm}$. In each unit cell, the top graphene-pattern composes of a graphene ring and four rectangular graphene bands. $R_{\text {in }}$ and $R_{\text {out }}$ are the radius of the inner and outer rings of graphene, respectively. $d_{1}, d_{g}, d_{2}$, and $t$ represent the thickness of $\mathrm{Si}$, gold mirror, $\mathrm{SiO}_{2}$ and graphene, respectively. In our calculation, the geometrical parameters are set as $d_{1}=3 \mu \mathrm{m}, d_{\mathrm{g}}=0.45 \mu \mathrm{m}, d_{2}=4.17 \mu \mathrm{m}, t=1 \mathrm{~nm}$, $R_{\text {in }}=0.8 \mu \mathrm{m}, R_{\text {out }}=1.05 \mu \mathrm{m}, D=0.2 \mu \mathrm{m}, L=0.7 \mu \mathrm{m}, G=0.25 \mu \mathrm{m}$, and $W=0.25 \mu \mathrm{m}$. The periods in both $x$ and $y$ directions are $2.5 \mu \mathrm{m}$. In the whole absorber structure, interspacing of unit elements is $0.4 \mu \mathrm{m}$. The total size of each manufactured device is $100 \mu \mathrm{m}$. 

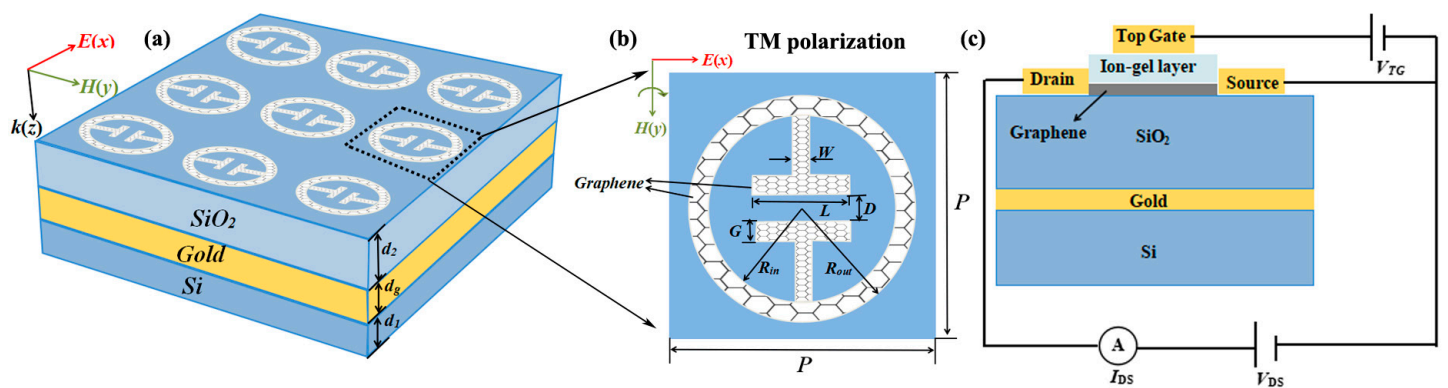

Figure 1. (a) Schematic of the perfect absorber structure; (b) the incident light polarization configuration (TM-polarization, TM-polarization indicates that the direction of the incident electric field is along the $\mathrm{x}$ axis); and (c) the schematic geometry of a top gate configuration to manipulate the Fermi energy of graphene. Parameters: $d_{1}=3 \mu \mathrm{m}, d_{\mathrm{g}}=0.45 \mu \mathrm{m}, d_{2}=4.17 \mu \mathrm{m}, t=1 \mathrm{~nm}, R_{\mathrm{in}}=0.8 \mu \mathrm{m}, R_{\text {out }}=1.05 \mu \mathrm{m}$, $D=0.2 \mu \mathrm{m}, L=0.7 \mu \mathrm{m}, G=0.25 \mu \mathrm{m}$, and $W=0.25 \mu \mathrm{m}$. The periods in both $x$ and $y$-directions are $2.5 \mu \mathrm{m}$. The whole structure resides on a substrate $\left(n_{1}=3.4\right)$.

The designed graphene metamaterials may be realized experimentally by the following procedures [27]: the $\mathrm{SiO}_{2}$ spacer and $\mathrm{Si}$ substrate are respectively coated on the upper and lower surfaces of Au through thermal evaporation, and then the monolayer graphene is coated on the top of the $\mathrm{SiO}_{2}$ spacer after a chemical vapor deposition (CVD), finally the cavity structures are fabricated on the monolayer graphene by electron beam etching.

The complex dielectric constant of gold at in the infrared regime is described by the Drude model with the plasma frequency $w_{p}=1.37 \times 10^{16} \mathrm{rad} / \mathrm{s}, e_{¥}=1$, and the damping constant $g_{c}=1.224 \times 10^{14}$ $\mathrm{rad} / \mathrm{s}[28-31]$.

$$
\varepsilon_{A u}(\omega)=\varepsilon_{\infty}-\omega_{p}^{2} /\left(\omega^{2}+i \gamma_{c} \omega\right)
$$

where $w$ is the angular frequency of the incident electromagnetic wave. The surface conductivity of signal-layer graphene $s$ can be described by the Kubo formula including interband and intraband transitions [32]. $k_{\mathrm{B}}, T$ and $E_{\mathrm{F}}$ are the Boltzmann constant, temperature, and Fermi level, respectively. When $E_{\mathrm{F}}>>k_{\mathrm{B}} T$, the interband transition dominates and surface conductivity can be simplified as [33-35]:

$$
\sigma(\omega)=\frac{e^{2} E_{F}}{\pi \hbar^{2}} \frac{i}{\omega+i / \tau}
$$

where $e, \hbar$ and $t$ represent the charge of an electron, reduced Planck's constant, and the relaxation of time, respectively. The relaxation time $t$ can be expressed as [36,37]:

$$
\tau=\frac{\mu E_{F}}{e v_{F}^{2}}
$$

where $\tau$ is dependent on the electron mobility $\mu=1 \times 10^{4} \mathrm{~cm}^{-2} \mathrm{~V}^{-1} \mathrm{~s}^{-1}$, and the Fermi velocity $v_{F}=1 \times 10^{6} \mathrm{~ms}^{-1}$. In this work, Fermi level $\left(E_{\mathrm{F}}=1.0 \mathrm{eV}\right)$, and the relaxation of time $(\tau=1.0 \mathrm{ps})$ are assumed. Under these conditions, the absorption response can be calculated by using the relation $A=1-R$ [38]. When the $R$ (reflection) approaches zero, $A$ can obtain perfect absorption.

As predicted from Equation (2), the surface conductivity of graphene can be tuned via manipulating its Fermi energy. At present, low top gate voltage can be used to increase the Fermi energy of graphene. Many gate dielectric materials such as 2D electron gas [39] indium tin oxide [40] monolayer $\mathrm{MoS}_{2}$ [41] and ion-gel [42] have been researched in the midinfrared and $\mathrm{THz}$ regime. Because ion-gel has good mechanical flexibility, fatigue stability, and excellent electrochemical and thermal stability, it can be compatible with tunable graphene plasmonic devices on various substrates [43,44]. Therefore, the most appropriate and common dielectric is an ion-gel with high capacitance [45]. The schematic geometry of a top gate configuration to control the Fermi energy of graphene is shown in Figure 1c. The ionic 
gel-layer applied between the graphene and gold electrodes induces carrier concentration and allows the absorber to enter the terahertz band [46-48].

\section{Simulation Results and Discussion}

For the whole structure, when parameters are set as mentioned above, two resonance responses with reflection and absorption are shown at around $22.5 \mu \mathrm{m}$ and $74.5 \mu \mathrm{m}$ in Figure $2 \mathrm{a}$. The absorption of Mode A and Mode B are $99.4 \%$ and $99.9 \%$, respectively. Figure $2 b$ shows the electric field distributions of the corresponding graphene at the resonance. It is observed that the electric field is concentrated mainly at the outer ring, inner edges, and corners of the graphene structure. Figure $2 \mathrm{c}$ shows the simulated surface charge density distributions at $\lambda_{1}=22.5 \mu \mathrm{m}$ and $\lambda_{2}=74.5 \mu \mathrm{m}$, respectively. For Mode $\mathrm{A}$ $\left(\lambda_{1}=22.5 \mu \mathrm{m}\right)$, the physical origin is related to the quadrupole resonances. For Mode B $\left(\lambda_{2}=74.5 \mu \mathrm{m}\right)$, the opposite charges are concentrated on both sides of the ring (left and right sides), which indicates the excitation of dipole resonance in the graphene metamaterials array.
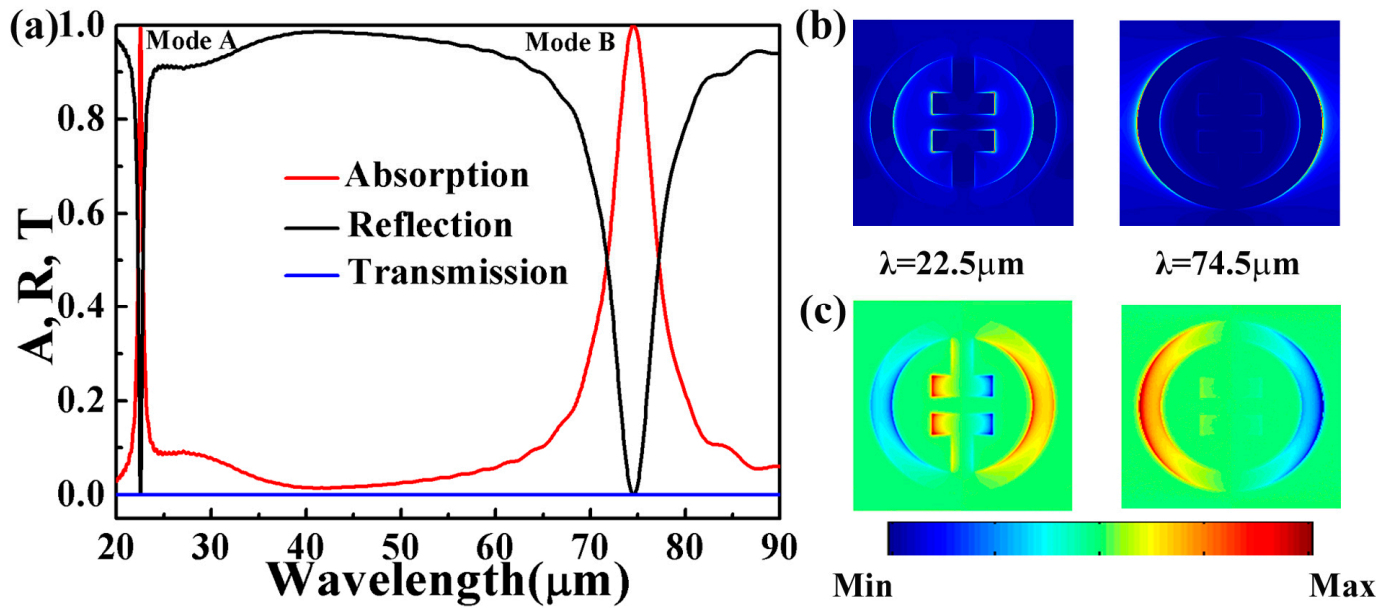

Figure 2. (a) Absorption (A), reflective (R), and transmission (T) spectrum of the presented structure; $(\mathbf{b}, \mathbf{c})$ are the electric field distribution of the corresponding graphene and the simulated surface charge density distributions at $\lambda_{1}=22.5 \mu \mathrm{m}$ and $\lambda_{2}=74.5 \mu \mathrm{m}$, respectively.

To further analyze the performance of dual-band absorber, we first study the effect of different geometric parameters by numerical simulation. Figure 3a shows the absorption spectrum of the dual-band absorber with changing the outer ring radius $\left(R_{\text {out }}\right)$ of graphene from $0.8 \mu \mathrm{m}$ to $1.05 \mu \mathrm{m}$. For Mode A, the absorption peak hardly changes. For Mode B, the maximum absorption decreases and peak wavelength experiences a blue shift as the $R_{\text {out }}$ increases. In Figure $3 \mathrm{~b}$, when $L$ increases, the distance of graphene arrays in the $x$-direction decreases, resulting in an enhancement in the coupling between them. This is the reason why Mode A experiences red shift and absorption enhancement of when $L$ increases. In Figure 3c, for Mode $\mathrm{A}$, different $D$ values also affect the absorption and peak wavelength. It can also be seen from Figure $2 b$ that the entire internal structure of the ring contributes to the excitation of mode A. Therefore, changing only one of the internal parameters may cause a complex change in its optical response. So we can see that when $D$ increases from 0.1 to $0.2 \mu \mathrm{m}$, the Mode A has experienced a red shift, and the absorption at $D=0.2 \mu \mathrm{m}$ is maximum. When $D$ increases to $0.25 \mu \mathrm{m}$, the positional shift of the peaks is no longer monotonous. This is because when $D>0.25 \mu \mathrm{m}$, the spacing between the internal structure and the inner ring is reduced, resulting in coupling enhancement and red shift.

When $D=0.2 \mu \mathrm{m}$, the absorption reaches the maximum. In Figure $3 \mathrm{~d}$, as $G$ increases, the absorption of Mode B hardly changes, while the absorption of Mode A slightly decreases and peak wavelength experiences a blue shift. In other words, the change of $G$ only affects the resonant wavelength of Mode A. 
(a)
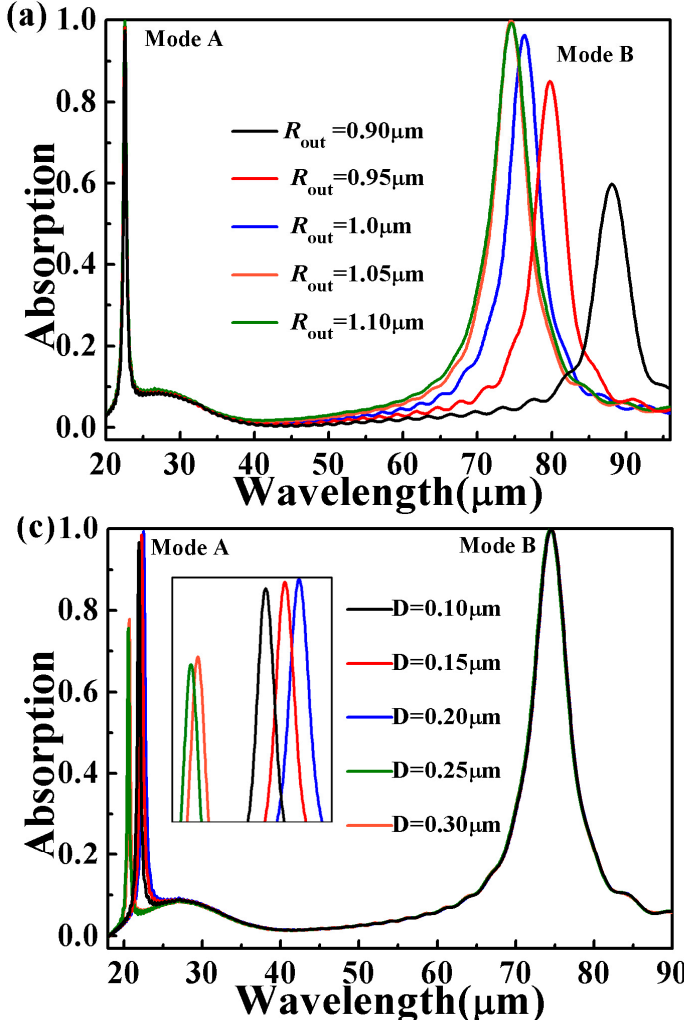
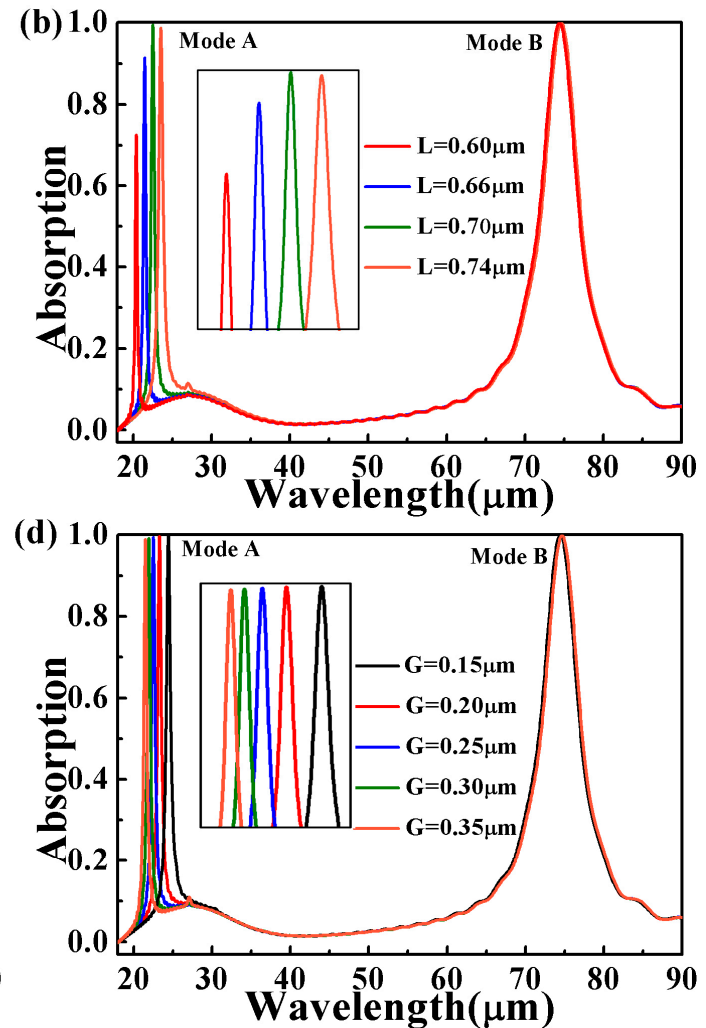

Figure 3. The effect of different parameters of the absorber on the absorption spectrum: (a) the outer ring radius of the graphene $\left(R_{\text {out }}\right) ;(\mathbf{b}) L,(\mathbf{c}) D,(\mathbf{d}) \mathrm{G}$. The Fermi level of graphene is $1.0 \mathrm{eV}$ in (b), (c), and $(\mathrm{d})$. The insert graph is the absorption peak of Mode A or Mode B.

Figure 4 shows the absorption spectrum with the size of $P$ changed from 2.4 to $2.7 \mu \mathrm{m}$. For Mode A, the peak first experiences a blue shift and then undergoes a red shift. The maximum absorption can be achieved when $P$ is equal to 2.4 or $2.5 \mu \mathrm{m}$. For Mode B, as the period varies, there is almost no change in absorption, but the absorption peak wavelength has a significant blue shift with the period increases. This is because the grating period is the determinant factor for the resonant frequency when the grating period $P$ matches the period of the plasmonic wave [49]. The change of absorption peak wavelength depends directly on the period of PA, which is consistent with Reference [50].

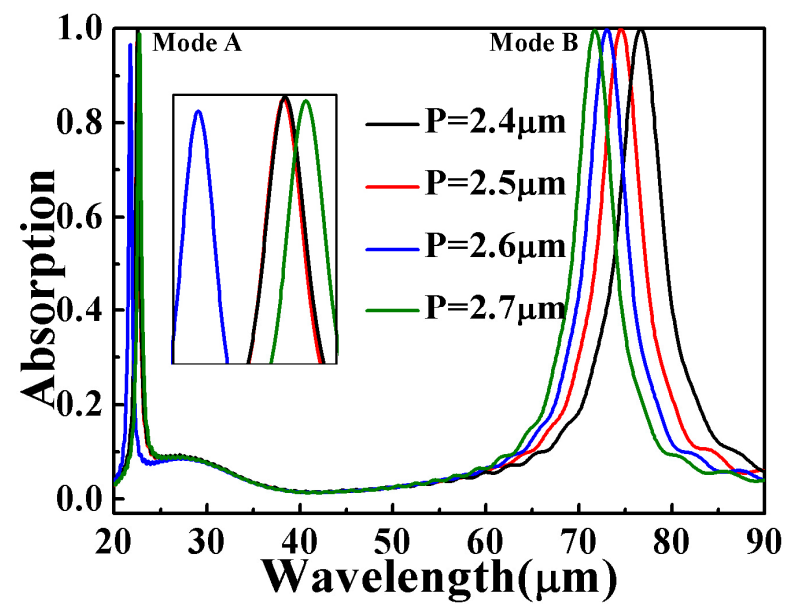

Figure 4. The absorption spectra of the proposed structure with different period $P$. The insert graph is the absorption peak of Mode A. 
From Figures $3 \mathrm{a}-\mathrm{d}$ and 4 , one can find that the influences of the structural parameters on absorption is independent of each other. Mode A and Mode B are generated by resonance of the internal structure and outer rings, respectively. It is indicated that our absorber offers great flexibility in the infrared regime. Therefore, by changing the dimensions of associated geometric parameters in the structure, two resonance wavelengths and the maximum absorption can be modulated individually while maintaining their dual-band characteristics.

However, for many metal absorbers or sensors, once their structures are fixed, their resonant wavelengths will no longer be tunable. Hence, we investigate the absorption spectrum of the absorber with the change of Fermi level $\left(E_{\mathrm{F}}\right)$ and relaxation time $(\tau)$. Figure 5 a shows the absorption spectrum of the absorber with different $E_{\mathrm{F}}$ values $(0.7-1.0 \mathrm{eV})$. The wavelengths of the absorption peaks have an obvious blue shift as the Fermi level $E_{\mathrm{F}}$ increases, but Mode A moves slowly than Mode B. As a whole, high $E_{\mathrm{F}}$ has a higher absorption relative to low $E_{\mathrm{F}}$. The physical mechanism is related to the absorption of graphene increases with the increase of graphene Fermi level $E_{\mathrm{F}}$ and local electric field, and the enhancement of graphene SPR resonance.

Figure $5 \mathrm{~b}$ shows the absorption spectrum for different $\tau$, with $E_{\mathrm{F}}=1.0 \mathrm{eV}$. The peak wavelength does not change, while the width of peak becomes narrow as $\tau$ increases. According to Equation (3), it can be known that the value of $\tau$ can be easily adjusted by changing $\mu$ (the carrier mobility). There is reference to provide methods for increasing carrier mobility by altering the surrounding environment, such as placing organic molecules on graphene [51]. More carrier mobility contributed to the plasmonic oscillation increases, resulting in higher absorption. But if $\tau$ is too large, the absorption will decrease due to most the energy being reflected. Therefore, as shown in Figure $5 b$, the maximum absorption increases at first and then decreases as $\tau$ increases. The absorption peaks can be saturated when $E_{\mathrm{F}}=1.0 \mathrm{eV}$ and $\tau=1.0 \mathrm{ps}$. The above result implies that the absorption spectrum can be tuned by changing Fermi level and relaxation time without changing the absorber geometry.
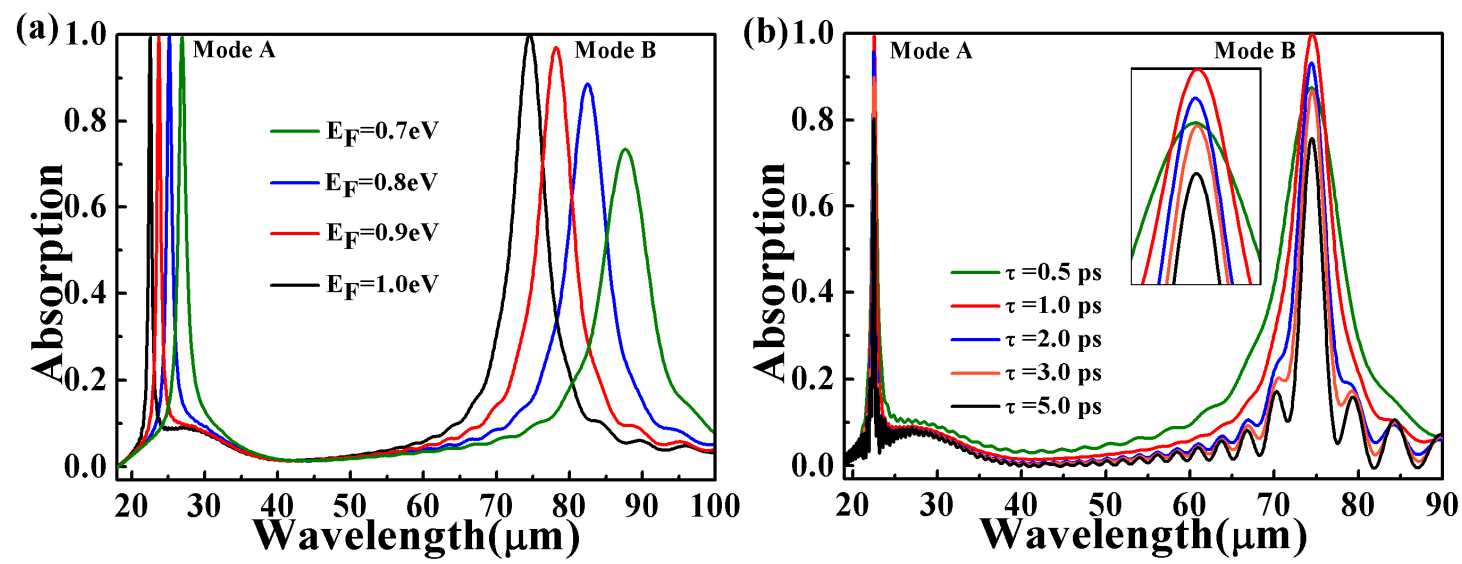

Figure 5. For TM polarization, (a) absorption spectrum of the absorber with different Fermi levels (the insert graph is absorption of Mode A) and (b) relaxation times. The insert graph is the absorption peak of Mode B.

To examine the sensing performance of the proposed dual-band PA, the dependence of the absorption spectrum on different surrounding refraction indices is calculated, with other parameters fixed (the same as in Figure 1). As shown in Figure 6a, the absorption peaks experience a red shift when the refractive index changes from 1.0 to 1.5 . The sensitivity (S) and figure of merit (FOM) are the important parameters for sensors [52,53]. $S$ and FOM can be expressed as $S=\Delta \lambda / \Delta n$ and $\mathrm{FOM}=\mathrm{S} / \mathrm{FWHM}$, respectively [54,55]. In Figure $6 \mathrm{~b}, \mathrm{c}$, the sensitivity can achieve 5.6 and $17.2 \mu \mathrm{m} / \mathrm{RIU}$, and the FOM of around 10.8 and 3.2, respectively. For Mode A, it has narrow bandwidth and the FOM can be as high as 10.8. The dipolar resonance mode (Mode B) of the graphene metamaterials has the highest index sensitivity, while the quadrupolar mode (Mode A) displays the highest FOM due to the narrow bandwidth. Table 1 shows that the comparison of sensitivity (S) and the figure of merit (FOM) 
of different structures proposed in previous publications [44,56-60]. It can be seen clearly that the proposed structure has better sensing performance.
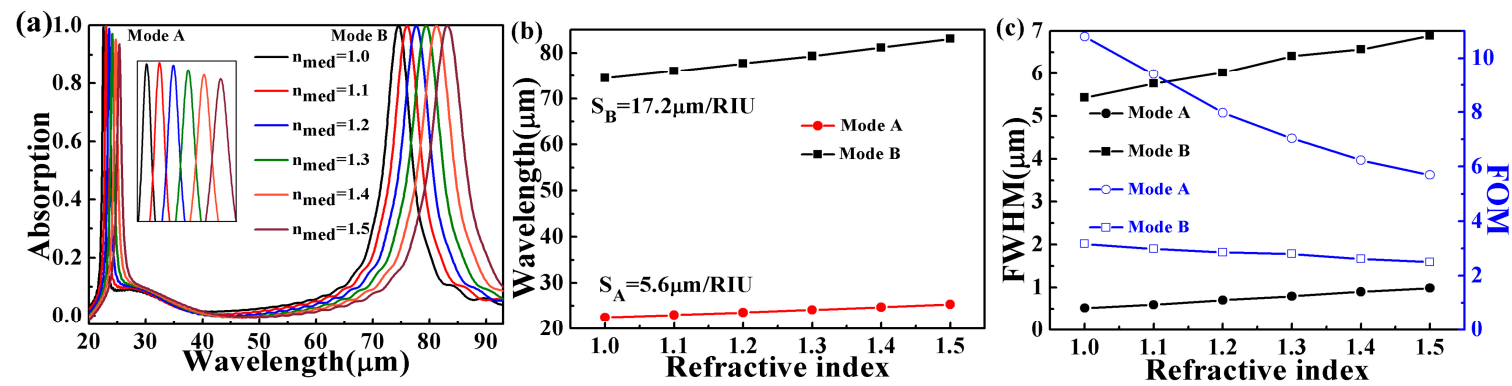

Figure 6. (a) Spectral shift of mode A and mode B with different sensing medium refractive indices (1.0-1.5) (the insert map is spectral shift of mode A); (b) a linear relationship of resonance wavelengths in response to changes in the refractive index; (c) FWHM (FWHM is the full width of half maximum) and figure of merit (FOM) of mode $\mathrm{A}$ and mode $\mathrm{B}$ in response to different sensing medium refractive indices.

Table 1. Comparison of sensitivity (S) and the figure of merit (FOM) of different structures proposed in previous publications.

\begin{tabular}{cccccccc}
\hline Reference & [44] & [56] & [57] & [58] & [59] & [60] & Proposed \\
\hline Sensitivity $(\max )(\mu \mathrm{m} / \mathrm{RIU})$ & 15.006 & 9.59 & 11.5 & 0.43 & 0.64 & 1 & 17.2 \\
\hline FOM (max) & 10.8 & 5.82 & 3.9 & 4.4 & 4.7 & 5 & 10.8 \\
\hline
\end{tabular}

The above result implies that that the PA-based RI sensor is highly dependent on the refractive index and has a large sensing range. Therefore, the dual-band PA-based RI sensor can be conveniently used as a device for monitoring or sensing refractive index changes of a tested agent.

\section{Conclusions}

To conclude, we theoretically propose a dual-band plasmonic perfect absorber (PA) and refractive index (RI) sensor based on graphene metamaterials. The numerical results indicate that the absorber can achieve absorptions of $99.4 \%$ and $99.9 \%$ at $22.5 \mu \mathrm{m}$ and $74.5 \mu \mathrm{m}$, respectively. Specifically, the absorption performance can be modulated by changing the Fermi level and the relaxation time without changing the geometric structure. Also, the PA-based RI sensor is highly dependent on the refractive index and has a large sensing range, which can achieve the sensitivities of around 5.6 and $17.2 \mu \mathrm{m} / \mathrm{RIU}$, and FOM of around 10.8 and 3.2, respectively. We believe that our study could provide a potential application in biosensing, tunable spectral detecting, environmental monitoring and medical diagnostics.

Author Contributions: Conceptualization, Z.Y., C.L. and X.C.; data curation, Z.Y., C.L. and X.C.; formal analysis, Z.Y., Z.Z., Y.T., X.Y., Y.Y., P.W. and J.W.; methodology, Z.Y., C.L. and P.W.; resources, Z.Y.; software, Y.Y. and P.W.; data curation, Z.Y.; writing—original draft preparation, Z.Y.; writing—review and editing, Z.Y., C.L. and X.C.

Funding: This research was funded by the National Natural Science Foundation of China (NNSFC) (51606158, 11604311, and 11704223), the Natural Science Foundation of Fujian Province (2018J05008 and JZ160459), the Sichuan Science and Technology Program (2018GZ0521), the Longshan Academic Talent Research Supporting program of SWUST (18lzx506), and the Postgraduate Innovation Fund Project by the Southwest University of Science and Technology (18ycx034).

Conflicts of Interest: The authors declare no conflict of interest. 


\section{References}

1. Choi, H.; Ko, S.J.; Choi, Y.; Joo, P.; Kim, T.; Lee, B.R.; Jung, J.W.; Choi, H.J.; Cha, M.; Jeong, J.R.; et al. Versatile surface plasmon resonance of carbon-dot-supported silver nanoparticles in polymer optoelectronic devices. Nat. Photonics 2013, 7, 732-738. [CrossRef]

2. Yan, Y.X.; Yang, H.; Yi, Z.; Li, R.S.; Wang, X.X. Enhanced Photocatalytic Performance and Mechanism of $\mathrm{Au} @ \mathrm{CaTiO}_{3}$ Composites with Au Nanoparticles Assembled on $\mathrm{CaTiO}_{3}$ Nanocuboids. Micromachines 2019, 10, 254. [CrossRef] [PubMed]

3. Di, L.J.; Yang, H.; Xian, T.; Chen, X.J. Facile synthesis and enhanced visible-light photocatalytic activity of novel p- $\mathrm{Ag}_{3} \mathrm{PO}_{4} / \mathrm{n}-\mathrm{BiFeO}_{3}$ heterojunction composites for dye degradation. Nanoscale Res. Lett. 2018, $13,257$. [CrossRef] [PubMed]

4. Di, L.J.; Yang, H.; Xian, T.; Liu, X.Q.; Chen, X.J. Photocatalytic and photo-Fenton catalytic degradation activities of $\mathrm{Z}$-scheme $\mathrm{Ag}_{2} \mathrm{~S} / \mathrm{BiFeO}_{3}$ heterojunction composites under visible-light irradiation. Nanomaterials 2019, 9, 399. [CrossRef] [PubMed]

5. Gao, H.J.; Wang, F.; Wang, S.F.; Wang, X.X.; Yi, Z.; Yang, H. Photocatalytic activity tuning in a novel $\mathrm{Ag}_{2} \mathrm{~S} / \mathrm{CQDs} / \mathrm{CuBi}_{2} \mathrm{O}_{4}$ composite: Synthesis and photocatalytic mechanism. Mater. Res. Bull. 2019, 115, 140-149. [CrossRef]

6. Zhao, X.X.; Yang, H.; Li, R.S.; Cui, Z.M.; Liu, X.Q. Synthesis of heterojunction photocatalysts composed of $\mathrm{Ag}_{2} \mathrm{~S}$ quantum dots combined with $\mathrm{Bi}_{4} \mathrm{Ti}_{3} \mathrm{O}_{12}$ nanosheets for the degradation of dyes. Environ. Sci. Pollut. Res. Int. 2019, 26, 5524-5538. [CrossRef] [PubMed]

7. Zeng, Y.; Chen, X.F.; Yi, Z.; Yi, Y.G.; Xu, X.B. Fabrication of p-n heterostructure ZnO/Si moth-eye structures: Antireflection, enhanced charge separation and photocatalytic properties. Appl. Surf. Sci. 2018, 441, 40-48. [CrossRef]

8. Zheng, C.X.; Yang, H. Assembly of $\mathrm{Ag}_{3} \mathrm{PO}_{4}$ nanoparticles on rose flower-like $\mathrm{Bi}_{2} \mathrm{WO}_{6}$ hierarchical architectures for achieving high photocatalytic performance. J. Mater. Sci. Mater. Electron. 2018, 29, 9291-9300. [CrossRef]

9. Cen, C.L.; Zhang, Y.B.; Liang, C.P.; Chen, X.F.; Yi, Z.; Duan, T.; Tang, Y.J.; Ye, X.; Yi, Y.G.; Xiao, S.Y. Numerical investigation of a tunable dual-band metamaterial perfect absorber consisting of two-intersecting graphene nanorings arrays. Phys. Lett. A 2019. [CrossRef]

10. Yi, Z.; Huang, J.; Cen, C.L.; Chen, X.F.; Zhou, Z.G.; Tang, Y.J.; Wang, B.Y.; Yi, Y.G.; Wang, J.; Wu, P.H. Nanoribbon-ring cross perfect metamaterial graphene multi-band absorber in $\mathrm{THz}$ range and the sensing application. Results Phys. 2019, 14, 102367. [CrossRef]

11. Geim, A.K. Graphene: Status and prospects. Science 2009, 324, 1530-1534. [CrossRef] [PubMed]

12. Liu, L.; Chen, J.J.; Zhou, Z.G.; Yi, Z.; Ye, X. Tunable absorption enhancement in electric split-ring resonators-shaped graphene array. Mater. Res. Express 2018, 5, 045802. [CrossRef]

13. Yi, Z.; Liu, L.; Wang, L.; Cen, C.; Chen, X.; Zhou, Z.; Ye, X.; Yi, Y.; Tang, Y.; Yi, Y.; et al. Tunable dual-band perfect absorber consisting of periodic cross-cross monolayer graphene arrays. Results Phys. 2019, $13,102217$. [CrossRef]

14. Liu, X.S.; Liu, G.Q.; Tang, P.; Fu, G.L.; Du, G.Z.; Chen, Q.Q.; Liu, Z.Q. Quantitatively optical and electrical-adjusting high-performance switch by graphene plasmonic perfect absorbers. Carbon 2018, 140, 362-367. [CrossRef]

15. Yi, Z.; Lin, H.; Niu, G.; Chen, X.F.; Zhou, Z.G.; Ye, X.; Duan, T.; Yi, Y.; Tang, Y.J.; Yi, Y.G. Triple-band plasmonic perfect metamaterial absorber with good angle-polarization-tolerance. Results Phys. 2019, 13, 102149. [CrossRef]

16. Liu, G.; Nie, Y.; Fu, G.; Liu, X.; Liu, Y.; Tang, L.; Liu, Z. Semiconductor meta-surface based perfect light absorber. Nanotechnology 2017, 28, 165202. [CrossRef]

17. Chen, X.F.; Cen, C.L.; Zhou, L.; Cao, R.F.; Yi, Z.; Tang, Y.J. Magnetic properties and reverse magnetization process of anisotropic nanocomposite permanent magnet. J. Magn. Magn. Mater. 2019, 483, $152-157$. [CrossRef]

18. Liu, Z.Q.; Tang, P.; Liu, X.S.; Yi, Z.; Liu, G.Q.; Wang, Y.; Liu, M.L. Truncated titanium/semiconductor cones for wide-band solar absorbers. Nanotechnology 2019, 30, 305203. [CrossRef]

19. He, Z.X.; Li, M.M.; Li, Y.H.; Li, C.C.; Yi, Z.; Zhu, J.; Dai, L.; Meng, W.; Zhou, H.Z.; Wang, L. ZrO 2 nanoparticle embedded carbon nanofibers by electrospinning technique as advanced negative electrode materials for vanadium redox flow battery. Electrochim. Acta 2019, 309, 166-176. [CrossRef] 
20. Zhang, B.X.; Zhao, Y.H.; Hao, Q.Z.; Kiraly, B.; Khoo, I.C.; Chen, S.F.; Huang, T.J. Polarization-independent dual-band infrared perfect absorber based on a metal-dielectric-metal elliptical nanodisk array. Opt. Express 2011, 19, 15221-15228. [CrossRef]

21. Xu, H.X.; Hu, L.Z.; Lu, Y.X.; Xu, J.; Chen, Y.H. Dual-band metamaterial absorbers in the visible and near-infrared regions. J. Phys. Chem. C 2019, 123, 10028-10033. [CrossRef]

22. Tang, L.; Liu, Y.; Liu, G.; Chen, Q.; Li, Y.; Shi, L.; Liu, Z.; Liu, X. A novel SERS substrate platform: Spatially stacking plasmonic hotspots films. Nanoscale Res. Lett. 2019, 14, 94. [CrossRef] [PubMed]

23. Wang, X.X.; Zhu, J.K.; Tong, H.; Yang, X.D.; Wu, X.X.; Pang, Z.Y.; Yang, H.; Qi, Y.P. A theoretical study of a plasmonic sensor comprising a gold nano-disk array on gold film with an $\mathrm{SiO}_{2}$ spacer. Chin. Phys. B 2019, 28, 044201. [CrossRef]

24. Liu, C.; Su, W.Q.; Wang, F.M.; Li, X.L.; Yang, L.; Sun, T.; Mu, H.W.; Paul, K.C. Theoretical assessment of a highly sensitive photonic crystal fibre based on surface plasmon resonance sensor operating in the near-infrared wavelength. J. Mod. Opt. 2019, 66, 1-6. [CrossRef]

25. Liu, C.; Yang, L.; Lu, X.L.; Liu, Q.; Wang, F.M.; Lv, J.W.; Sun, T.; Mu, H.W.; Paul, K.C. Mid-infrared surface plasmon resonance sensor based on photonic crystal fibers. Opt. Express 2017, 25, 14227-14237. [CrossRef] [PubMed]

26. Balandin, A.A.; Ghosh, S.; Bao, W.; Calizo, I.; Teweldebrhan, D.; Miao, F.; Lau, C.N. Superior thermal conductivity of single-layer grapheme. Nano Lett. 2008, 8, 902-907. [CrossRef] [PubMed]

27. Ghamsari, B.G.; Olivieri, A.; Variola, F.; Berini, P. Enhanced Raman scattering in graphene by plasmonic resonant Stokes emission. Nanophotonics 2014, 3, 363-371. [CrossRef]

28. Zhang, Q.B.; Liao, J.; Liao, M.; Dai, J.Y.; Ge, H.L.; Duan, T.; Yao, W.T. One-dimensional Fe $7 \mathrm{~S}_{8} @ \mathrm{C}$ nanorods as anode materials for high-rate and long-life lithium-ion batteries. Appl. Surf. Sci. 2019, 473, 799-806. [CrossRef]

29. Xiong, Z.; Cao, L. High magnetic-dielectric tunability in Ni nanocrystals embedded $\mathrm{BaTiO}_{3}$ films. J. Alloys Compd. 2019, 785, 200-205. [CrossRef]

30. Li, C.C.; Xie, B.S.; Chen, J.; He, Z.X.; Chen, Z.S.; Long, Y. Emerging mineral-coupled composite phase change materials for thermal energy storage. Energy Convers. Manag. 2019, 183, 633-644. [CrossRef]

31. Luo, X.; Liu, Z.M.; Wang, L.L.; Liu, J.P.; Lin, Q. Tunable ultra-narrowband and wide-angle graphene-based perfect absorber in the optical communication region. Appl. Phys. Express 2018, 11, 105102. [CrossRef]

32. Zhang, X.W.; Qi, Y.P.; Zhou, P.Y.; Gong, H.H.; Hu, B.B.; Yan, C.M. Refractive Index Sensor Based on Fano Resonances in Plasmonic Waveguide With Dual Side-Coupled Ring Resonators. Photonic Sens. 2018, 8 , 367-374. [CrossRef]

33. Wang, J.; Yang, L.; Wang, M.; Hu, Z.D.; Deng, Q.L.; Nie, Y.G.; Zhang, F.; Sang, T. Perfect absorption and strong magnetic polaritons coupling of graphene-based silicon carbide grating cavity structures. J. Phys. D Appl. Phys. 2019, 52, 015101. [CrossRef]

34. Liu, C.; Yang, L.; Liu, Q.; Wang, F.M.; Sun, Z.J.; Sun, T.; Mu, H.W.; Paul, K.C. Analysis of a Surface Plasmon Resonance Probe Based on Photonic Crystal Fibers for Low Refractive Index Detection. Plasmonics 2018, 13, 779-784. [CrossRef]

35. Ding, P.; Li, Y.; Shao, L.; Tian, X.M.; Wang, J.Q.; Fan, C.Z. Graphene aperture-based metalens for dynamic focusing of terahertz waves. Opt. Express 2018, 26, 28038-28050. [CrossRef] [PubMed]

36. Li, R.; Xiao, W.; Miao, C.; Fang, R.; Wang, Z.Y.; Zhang, M.Q. Sphere-like $\mathrm{SnO}_{2} / \mathrm{TiO}_{2}$ composites as high-performance anodes for lithium ion batteries. Ceram. Int. 2019, 45, 13530-13535. [CrossRef]

37. He, X.K.; Sun, Z.Y.; Zou, Q.T.; Wu, L.Y.; Jiang, J.B. Electrochemical Behavior of Co(II) Reduction for Preparing Nanocrystalline Co Catalyst for Hydrogen Evolution Reaction from 1-ethyl-3-methylimidazolium Bisulfate and Ethylene Glycol System. J. Electrochem. Soc. 2019, 166, 57-64. [CrossRef]

38. Wang, X.X.; Bai, X.L.; Pang, Z.Y.; Zhu, J.K.; Wu, Y.; Yang, H.; Qi, Y.P.; Wen, X.L. Surface-enhanced Raman scattering by composite structure of gold nanocube-PMMA-gold film. Opt. Mater. Express 2019, 9, 1872-1881. [CrossRef]

39. Choi, B.R.; Hansen, A.E.; Kontos, T.; Hoffmann, C.; Oberholzer, S.; Belzig, W.; Schonenberger, C.; Akazaki, T.; Takayanagi, H. Shot-noise and conductance measurements of transparent superconductor/two-dimensional electron gas junctions. Phys. Rev. B 2005, 72, 024501. [CrossRef] 
40. Guo, B.; Wang, S.; Wu, Z.; Wang, Z.; Wang, D.; Huang, H.; Zhang, F.; Ge, Y.; Zhang, H. Sub-200 fs soliton mode-locked fiber laser based on bismuthene saturable absorber. Opt. Express 2018, 26, 22750-22760. [CrossRef]

41. Cen, C.L.; Yi, Z.; Zhang, G.F.; Zhang, Y.B.; Liang, C.P.; Chen, X.F.; Tang, Y.J.; Ye, X.; Yi, Y.G.; Wang, J.; et al. Theoretical design of a triple-band perfect metamaterial absorber in the THz frequency range. Results Phys. 2019, 14, 102463. [CrossRef]

42. Fang, Z.; Thongrattanasiri, S.; Schlather, A.; Liu, Z.; Ma, L.; Wang, Y.; Ajayan, P.M.; Nordlander, P.; Halas, N.J.; García de Abajo, F.J. Gated tunability and hybridization of localized plasmons in nanostructured graphene. ACS Nano 2013, 7, 2388-2395. [CrossRef] [PubMed]

43. Hu, H.; Zhai, F.; Hu, D.; Li, Z.; Bai, B.; Yang, X.; Dai, Q. Broadly tunable graphene plasmons using an ion-gel top gate with low control voltage. Nanoscale 2015, 7, 19493-19500. [CrossRef] [PubMed]

44. Zhang, Y.B.; Cen, C.L.; Liang, C.P.; Yi, Z.; Chen, X.F.; Li, M.W.; Zhou, Z.G.; Tang, Y.J.; Yi, Y.G.; Zhang, G.F. Dual-band switchable terahertz metamaterial absorber based on metal nanostructure. Results Phys. 2019, 14, 102422. [CrossRef]

45. Shi, X.L.; Ma, L.J.; Zhang, Z.D.; Tang, Y.; Zhang, Y.J.; Han, J.Q.; Sun, Y.Q. Dual Fano resonance control and refractive index sensors based on a plasmonic waveguide-coupled resonator system. Opt. Commun. 2018, 427, 326-330. [CrossRef]

46. Das, A.; Pisana, S.; Chakraborty, B.; Piscanec, S.; Saha, S.K.; Waghmare, U.V.; Novoselov, K.S.; Krishnamurthy, H.R.; Geim, A.K.; Ferrari, A.C.; et al. Monitoring dopants by Raman scattering in an electrochemically top-gated graphene transistor. Nat. Nanotechnol. 2008, 3, 210-215. [CrossRef] [PubMed]

47. Cho, J.H.; Lee, J.; Xia, Y.; Kim, B.S.; He, Y.; Renn, M.J.; Lodge, T.P.; Frisbie, C.D. Printable ion-gel gate dielectrics for low-voltage polymer thin-film transistors on plastic. Nat. Mater. 2008, 7, 900-906. [CrossRef] [PubMed]

48. Ju, L.; Geng, B.; Horng, J.; Girit, C.; Martin, M.; Hao, Z.; Bechtel, H.A.; Liang, X.; Zettl, A.; Shen, Y.R.; et al. Graphene plasmonics for tunable terahertz metamaterials. Nat. Nanotechnol. 2011, 6, 630-634. [CrossRef] [PubMed]

49. Chen, J.; Zhang, T.; Tang, C.J.; Mao, P.; Liu, Y.J.; Yu, Y.; Liu, Z.Q. Optical Magnetic Field Enhancement via Coupling Magnetic Plasmons to Optical Cavity Modes. IEEE Photonics Technol. Lett. 2016, 28, 1529-1532. [CrossRef]

50. Deng, Y.H.; Yang, Z.J.; He, J. Plasmonic nanoantenna-dielectric nanocavity hybrids for ultrahigh local electric field enhancement. Opt. Express 2018, 26, 31116-31128. [CrossRef]

51. Zheng, Z.M.; Li, P.; Huang, J.; Liu, H.D.; Zao, Y.; Hu, Z.L.; Zhang, L.; Chen, H.X.; Wang, M.S.; Peng, D.L.; et al. High performance columnar-like $\mathrm{Fe}_{2} \mathrm{O}_{3} @$ carbon composite anode via yolk@ shell structural design. J. Energy Chem. 2020, 41, 126-134. [CrossRef]

52. Cheng, S.B.; Xia, T.; Liu, M.S.; Gao, S.F.; Xu, S.; Zhang, G.; Tao, S.H. Optical manipulation of microparticles with the momentum flux transverse to the optical axis. Opt. Laser Technol. 2019, 113, 266-272. [CrossRef]

53. Wang, X.X.; Wu, X.X.; Zhu, J.K.; Pang, Z.Y.; Yang, H.; Qi, Y.P. Theoretical investigation of a highly sensitive refractive-index sensor based on TM0 waveguide mode resonance excited in an asymmetric metal-cladding dielectric waveguide structure. Sensors 2019, 19, 1187. [CrossRef] [PubMed]

54. Tang, J.Q.; Gao, K.P.; Ou, Q.H.; Fu, X.W.; Man, S.Q.; Guo, J.; Liu, Y.K. Calculation extinction cross sections and molar attenuation coefficient of small gold nanoparticles and experimental observation of their UV-vis spectral properties. Spectrochim. Acta A Mol. Biomol. Spectrosc. 2018, 191, 513-520. [CrossRef] [PubMed]

55. Ma, X.; Xie, M.; Wu, W.Q.; Zeng, B.; Wang, Y.; Wu, X.X. The novel fractional discrete multivariate grey system model and its applications. Appl. Math. Model. 2019, 70, 402-424. [CrossRef]

56. Wang, J.C.; Yang, L.; Hu, Z.D.; He, W.J.; Zheng, G.G. Analysis of graphene-based multilayer comb-like absorption enhancement system based on multiple waveguide theory. IEEE Photonics Technol. Lett. 2019, 31, 561-564. [CrossRef]

57. Huang, J.; Niu, G.; Yi, Z.; Chen, X.F.; Zhou, Z.G.; Ye, X.; Tang, Y.J.; Duan, T.; Yi, Y.; Yi, Y.G. High sensitivity refractive index sensing with good angle and polarization tolerance using elliptical nanodisk graphene metamaterials. Phys. Scr. 2019, 94, 085805. [CrossRef]

58. Le, K.Q.; Ngo, Q.M.; Nguyen, T.K. Nanostructured metal-insulator-metal metamaterials for refractive index biosensing applications: Design, fabrication, and characterization. IEEE J. Sel. Top. Quant. 2016, 23, 6900506. [CrossRef] 
59. Le, K.Q.; Alù, A.; Bai, J. Multiple Fano interferences in a plasmonic metamolecule consisting of asymmetric metallic nanodimers. J. Appl. Phys. 2015, 117, 023118. [CrossRef]

60. Liu, Z.Q.; Shao, H.B.; Liu, G.Q. $\lambda^{3} / 20000$ plasmonic nanocavities with multispectral ultra-narrowband absorption for high-quality sensing. Appl. Phys. Lett. 2014, 104, 081116. [CrossRef]

(C) 2019 by the authors. Licensee MDPI, Basel, Switzerland. This article is an open access article distributed under the terms and conditions of the Creative Commons Attribution (CC BY) license (http://creativecommons.org/licenses/by/4.0/). 